\title{
Integrated Mobile GIS and Wireless Internet Map Servers for Environmental Monitoring and Management
}

\author{
Ming-Hsiang Tsou
}

\begin{abstract}
With the progress of mobile GIS technology there is a great potential for adopting wireless communications and Internet mapping services for regional environmental management programs and natural habitat conservation. This paper provides an overview of a NASA-funded research project that focuses on the development of mobile GIS tools and wireless Internet Map Server (IMS) services to facilitate environmental monitoring and management tasks. By developing and testing wireless web-based map/image servers, mobile GIS applications, and global positional systems (GPS), this research created an integrated software/hardware infrastructure for a prototype mobile GIS application. The mobile GIS prototype allows multiple resource managers and park rangers to access large-size, remotely sensed images and GIS layers from a portable web server mounted in a vehicle. Users can conduct real-time spatial data updates and/or submit changes back to the web server over the wireless local area network (WLAN). This paper discusses in general the major components of mobile GIS, their current technological limitations, and potential problems during implementation. Key research agenda for mobile GIS are identified with suggestions for future research and development.
\end{abstract}

KEYWORDS: Internet mapping, mobile GIS, GPS, wireless communication

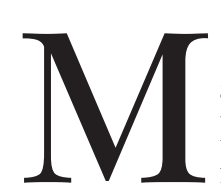

\section{Introduction}

any environmental problems and habitat-monitoring tasks require near real-time field mapping and precise positional information. These tasks are time consuming and difficult using traditional field mapping and geographic information systems (GIS) techniques (Angold et al. 1996), which are often further limited to desktop computers and hard-wired network communications. Moreover, traditional GIS and remote sensing software packages are expensive, and they are perceived as complicated by field workers who lack advanced remote sensing and GIS skills or training. A possible solution is to adopt mobile GIS services that can integrate GIS, global positioning systems (GPS), and remote sensing capabilities for accessing geospatial data sets via mobile devices.

There are many advantages to using mobile GIS devices for environmental management and habitat monitoring. Field workers can easily carry mobile GIS devices to field locations for their data collection and validation tasks. With wireless communication capability, users can perform real-time data updates and exchanges between the centralized map servers

Ming-Hsiang Tsou, Assistant Professor, Department of Geography, San Diego State University, San Diego CA 92182-4493. E-mail: $<$ mtsou@mail.sdsu.edu $>$. and distributed mobile clients. Another advantage of a mobile GIS solution is that the GIS framework can be integrated with GPS equipment seamlessly to provide comprehensive geodetic measurements and navigation functions.

Mobile GIS is an integrated technological framework for the access of geospatial data and location-based services through mobile devices, such as Pocket PCs, Personal Digital Assistants (PDA), or smart cellular phones. With the advancement and convergence of GPS, Internet, and wireless communication technologies, mobile GIS has a great potential to play an important role in field data acquisition and validation (Pundt 2002) and in emergency vehicle routing services (Derekenaris et al. 2001). Today there is a rapidly increasing number of mobile GIS applications being established by private companies (Crisp 2003), government agencies, and academic research institutes.

The main users of mobile GIS are field workers and consumers of location-based services (Peng and Tsou 2003). For example, an environmental scientist in a national park can use GPS and mobile GIS devices to validate, add, or delete the locations of sensitive plant species. A shopper can use a smart phone to locate a nearby shopping mall and create the shortest routing path for navigation to it. A police officer can use a Pocket PC to report a traffic accident with accurate geospatial locations and send the report directly to the command and control 
center via wireless networks. These mobile GIS applications utilize different types of technologies, software packages, and hardware devices. Sometimes they are referred to by different names, such as field-based GIS (Pundt and BrinkkotterRunde 2000), location-based services (LBS) (OGC 2003a; Peng and Tsou 2003), wireless GIS mapping (Xue et al. 2002) and telecartography (Gartner 2003). Actually, the differences in these names reflect the complicated nature of mobile GIS applications and the dramatic progress of related GIS/telecommunication technologies. The following paragraph provides a clear definition of "mobile GIS" and explains the differences between the terminologies used in different mobile GIS applications.

This paper defines the term mobile GIS as an integrated software/hardware framework for the access of geospatial data and services through mobile devices via wireline or wireless networks. There are two major application areas of mobile GIS: field-based GIS and location-based services. Field-based GIS focuses on GIS data collection, and data validation and update in the field, such as adding new point data or changing the attribute tables on an existing GIS dataset. Location-based services focus on business-oriented location management functions, such as navigation, street routing, finding a specific location, or tracking a vehicle (Jagoe 2002; OGC 2003b). The major differences between the field-based GIS and LBS are the data editing capabilities. Most field-based GIS applications need to edit or change the original GIS data or modify their attributes. Location-based services rarely change original GIS datasets but rather use them as the background or reference maps for navigation or tracking purposes. Wireless GIS mapping is a subcategory of mobile GIS technology that focuses on the wireless networking capability of mobile GIS services.
Major Applications for Field-based GIS

- Environmental monitoring and natural resource management

- Ecological/geographic research (field data collection

- Utilities maintenance (electric, gas, and water)

- Asset management systems (parcels, lands)

- Educational travel (field trips)

- Emergency response and hazard management

\section{Major Applications for LBS}

- Directory assistance (location-based yellow pages, nearby stores or commercial services)

- Vehicle navigation (real-time traffic report and routing functions)

- Business transaction services (location-based transaction verifications, purchasing)

- Address query/mapping services

- Geo-tracking services (package delivery, bus schedules, monitoring vehicle locations)

- Emergency response (911 calls)

- Real estate management

- Social interaction services (looking for friends and children, arranging dating) management
Table 1. Mobile GIS applications and major technologies.

Table 1 itemizes the major technologies used or considered in field-based GIS and LBS and their major application areas. In general, the field-based GIS technologies emphasize the more comprehensive GIS functions, which require computationally intensive devices and larger display screens, such as Pocket and Tablet PCs. Most field-based GIS software packages are cross-platform and independent of hardware devices. On the other hand, LBS technologies focus on creating commercial value from location information. Each mobile phone system or vehicle-based computer has its own proprietary operating system that is usually very difficult to customize. To clarify the basic requirements of a mobile GIS framework, the next section explains the generic architecture of mobile GIS.

\section{The Architecture of Mobile GIS}

The architecture of the mobile GIS is very similar to that of the Internet GIS. It follows the client/ server architecture as is traditional in Internet GIS 
applications. The client-side mobile GIS components are the end-user hardware devices that can display maps or provide analytical results of GIS operations. The server-side components provide comprehensive geospatial data and perform GIS operations based on requests from the client-side components. Between the client and the server there are various types of communication networks (such as wired cable connections or wireless communications) to facilitate the exchanges of geodata and services. Figure 1 illustrates the six basic components of mobile GIS: (1) positioning systems; (2) mobile GPS receivers; (3) mobile GIS software; (4) data synchronization/wireless communication components; (5) geospatial data; and (6) GIS content servers.

Positioning systems are the devices that can provide georeferenced coordinate information (X, Y, and Z-elevation) to mobile GIS receivers. There are two major systems, local positioning systems and global positioning systems (GPS). Local positioning systems rely on triangulation of the radio signals or cellular phone signals from multiple base stations in order to calculate the position of a device. Global positioning systems use satellite signals to calculate the position of GPS units. Sometimes, mobile GIS applications may require both types of positioning systems within urban areas to generate satisfactory results.

Mobile GIS receivers are small-sized computers or terminals that can display maps and locational information to end users. Their hardware components include CPU, memory, storage devices, input/output connections, and display (screen) functions. Pocket PCs, smart phones, tablet PCs or PDAs are the most popular mobile GIS receivers. Notebook computers can become mobile GIS receivers if connected to GPS and other mobile GIS components. However, most mobile GIS receivers require a very small-sized hardware device to achieve portability. The major differences between small mobile GIS receivers and the traditional desktop personal computer are smaller screen resolutions (240x300), limited storage space, and slower CPU speed (Wintges 2003). Some high-end mobile GIS receivers equipped with wireless communication devices can be used for data exchange and telecommunications between the receivers and the content servers. Alternatively, mobile GIS receivers may rely on serial or USB cables to transfer data between the content servers and the handheld devices.

Mobile GIS software refers to the specialized GIS software packages employed by mobile GIS applications. Due to the limitations of mobile GIS receivers (smaller display units, limited storage), the design of mobile GIS software needs to focus on specific GIS operations (such as geocoding, address matching, spatial search, routing services, or map display) rather than comprehensive GIS functions. For example, the functional design of LBS software is quite different from the functions provided in field-based GIS packages. Most mobile GIS software packages are lightweight, customizable, and can cope with positional systems (such as GPS tracking functions). Different mobile GIS software may require different operating systems (such as Windows CE or Palm OS).

Geospatial data are customized GIS layers or remotely sensed imagery used in mobile GIS applications. With the limited storage space in mobile GIS receivers, most GIS data need to be compressed or presented as subsets of their original extents. Usually, mobile GIS receivers will store geospatial data in a geodata cache located in a temporary GIS storage space or a flash memory card. Often customized datasets are downloaded and synchronized from GIS content servers. One alternative approach is to utilize wireless communications to access large-sized GIS layers and/or remotely sensed imagery from the content server directly. The advantage of direct wireless access is that mobile GIS users can retrieve the most up-todate geospatial information directly from the content server without encountering the complicated data synchronization process between the mobile GIS receivers and the content servers.

The data synchronization/wireless communication component is the communication mechanism linking the mobile GIS receivers with GIS content servers. These linkages could be real-time wireless communications (via Wi-Fi or cellular phone signals) or cable-based data synchronization communications (via USB or serial ports). Both mechanisms should provide twoway communications. For cable-based connections, the GIS content servers can send geodata to the receivers (stored in geodata cache) and the receiver can upload updated geodata back to the content server. For wireless communication, the mobile GIS receivers can request a specific service or map from the GIS content server, and the server will respond to the request by sending the new map to the receiver. To facilitate the two-way communications, several middleware or data synchronization software packages (such as Microsoft ActiveSync or Web Services) are required for mobile GIS applications. If both mobile receivers and GIS content servers have networking capabilities, the Internet can become a very effective communication channel for mobile GIS applications.

GIS content servers are stand-alone GIS workstations or web-based servers that provide geospatial data or map services to mobile GIS receivers. Most 


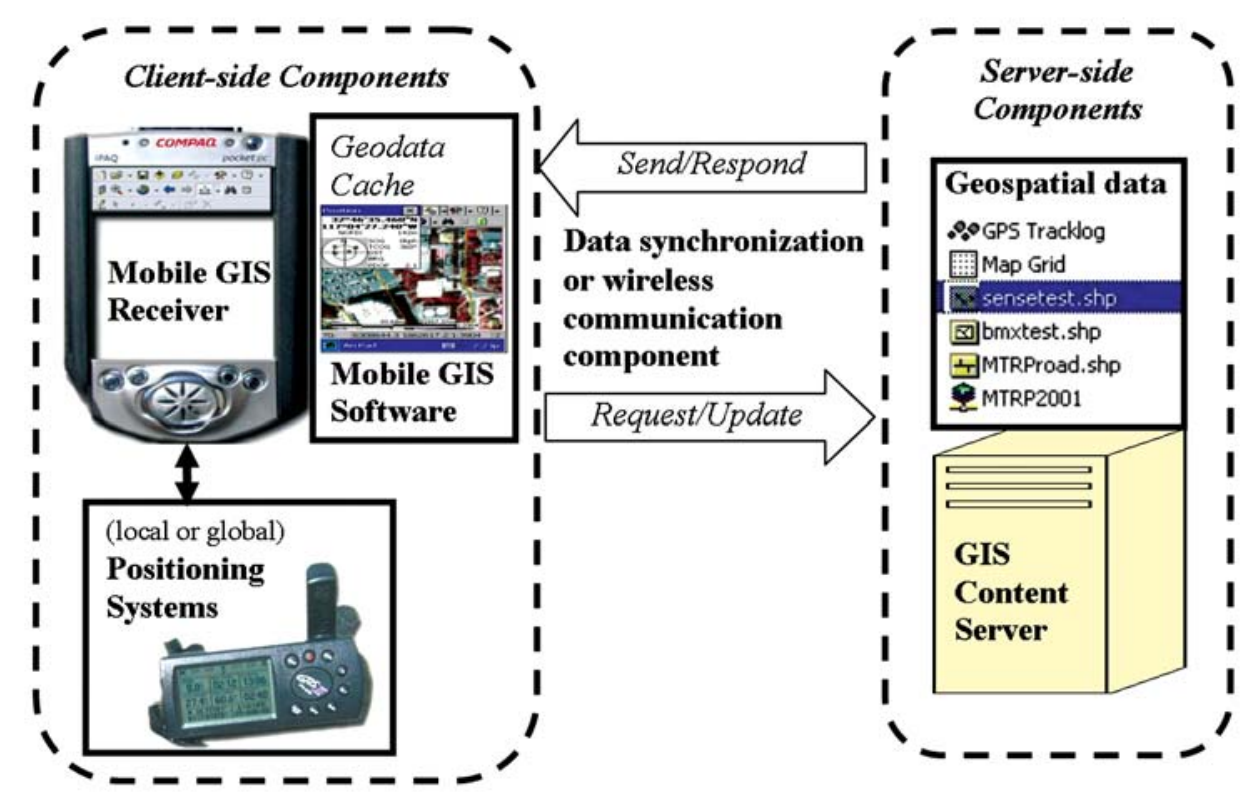

Figure 1. The architecture of mobile GIS.

cable-based mobile GIS receivers use a stand-alone GIS workstation as the content server. Wireless-based mobile GIS receivers may require advanced web servers or wireless Internet map servers for accessing geospatial data. Sometimes, one mobile GIS receiver may be used to access multiple web-based servers at the same time to integrate multiple GIS layers. A single GIS content server can also provide data and services to multiple mobile GIS receivers simultaneously.

Figure 1 illustrates a very generic mobile GIS architecture. Different mobile GIS applications may have unique settings or additional components. For example, landscape architects may use a remotely sensed image as a background to draw a preliminary design of a tree line without the GPS component. Some sensitive data or classified mobile GIS operations may become stand-alone units without any external communication mechanisms (for security reasons). The next section introduces a mobile GIS application for environmental monitoring tasks which employs a local wireless communication network and a network-based mapping server.

\section{Developing Mobile GIS for Environmental Monitoring}

The goal of this research is to respond to the need for wireless, web-based analytical tools to process remotely sensed imagery used by field participants in natural habitat conservation and land management programs. The project focused on the development of a mobile GIS architecture to provide basic operational, user-friendly remotesensing capabilities to a diverse user community of natural resource managers. Multiple resource management agencies, organizations, and commercial partners participated in this project, including: Mission Trail Regional Park at San Diego, California; the Field Stations Office at San Diego State University (SDSU); Ed Almanza and Associates; and the Nature Conservancy of Orange County, California.

The project team developed a portable, wireless web-based image server integrated with mobile Pocket PC and GPS receivers, and demonstrated real-time GIS and remote sensing analysis capabilities in the field. Several user scenarios were developed to demonstrate the capability of real-time monitoring and the change detection tasks typically required in natural habitat reserves by resource managers. The mobile remote sensing and GIS data collection and analysis solution provides a user-friendly, easy to use interface that allows park rangers and resource managers to access and analyze land-cover changes and remotely sensed images in the field.

The most unique feature of this mobile GIS application is the establishment of a wireless communication channel between an Internet map server (IMS) and a mobile GIS receiver. Currently, most mobile 


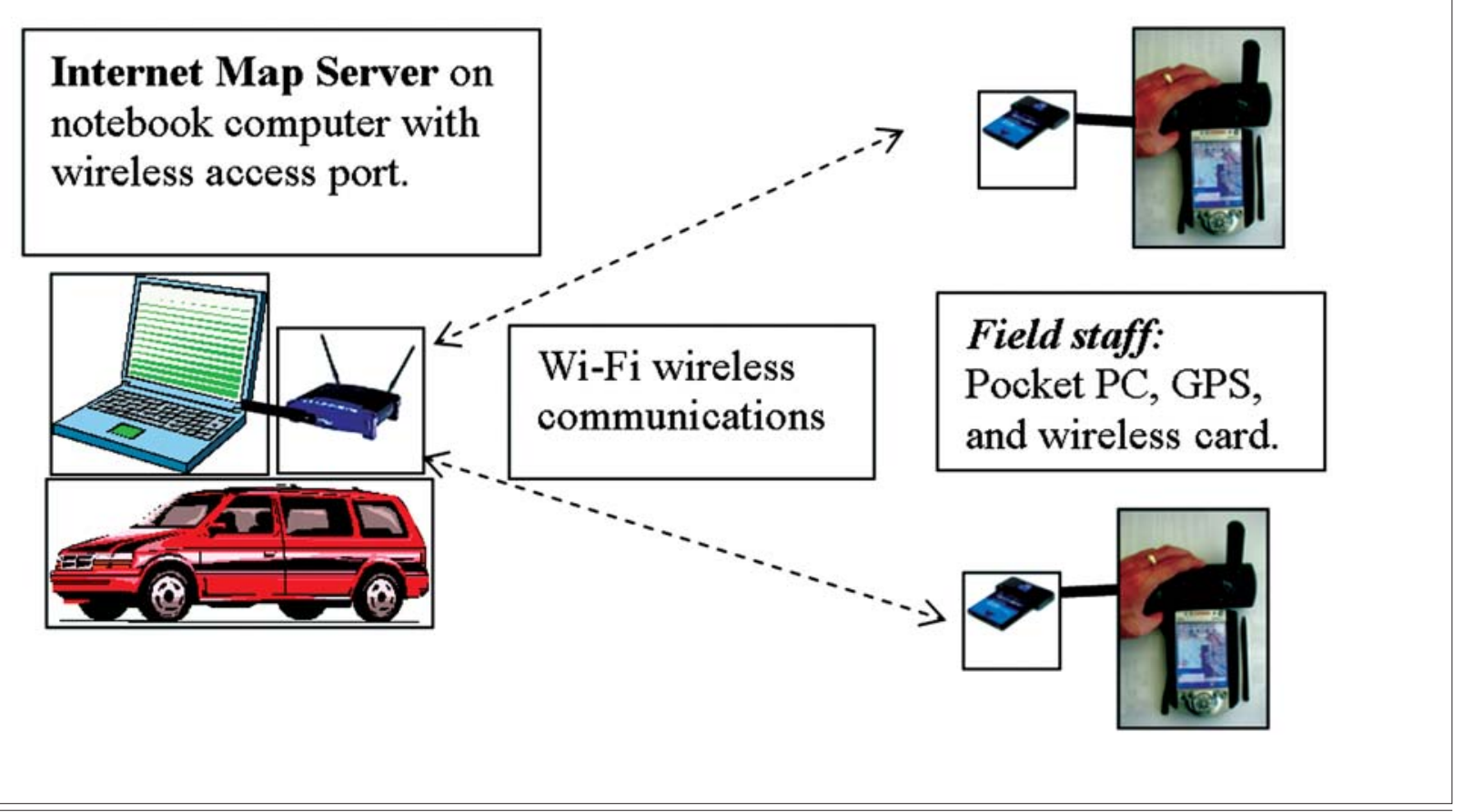

Figure 2. Wireless local area network solution for mobile GIS.

GIS receivers (Pocket or Tablet PCs) provide very limited storage capacity (64Mb to $128 \mathrm{Mb}$ ) for field GIS applications. Wireless-based IMS can transfer very large remotely sensed images or extensive GIS map layers (up to $4 \mathrm{~GB}$ or $8 \mathrm{~GB}$ ) to mobile devices via local wireless communications quickly. The link to wireless IMS improves the capacity of mobile GIS significantly. Multiple users can access a centralized IMS simultaneously without extra costs. Also, the IMS can allow multiple mobile GIS users to synchronize their GIS databases at the same time, without the need to update GIS data layers and images one by one.

The following sections highlight the three major elements of this project: mobile wireless local area networks, customized mobile GIS software and receiver devices, and web-based GIS content servers.

\section{Mobile Wireless Local Area Networks}

The first and most substantial task of the project was to establish a wireless local area network for the communications between mobile GIS receivers and Internet map servers. In the prototype, an Internet map server (ESRI ArcIMS 4.0) was installed on a notebook computer (Toshiba Tecra 8100) equipped with a wireless access port (Linksys Wireless Access Point Router). The notebook and wireless access port were placed inside a vehicle to obtain electrical power from the cigarette lighter socket for wireless communications. Field staff then used Pocket PCs equipped with GPS and wireless PCMIA cards to access remotely sensed imagery and GIS data layers from a large capacity database residing on the notebook web server via wireless communication channels (Wi-Fi). Figure 2 illustrates the architecture of the wireless local area network solution of mobile GIS.

Several possible technologies can be used for wireless data communication, including infrared, radio, microwave, and laser transmissions. The most popular techniques are infrared and radio signals that can be used to create Wireless Local Area Networks (wireless LAN). A wireless LAN refers to the use of wireless communication technologies to connect PCs, laptops, printers, and hand-held devices to traditional hardwired networks over short distances (Jagoe 2002). For devices to communicate with each other through a wireless media, a wireless network adapter card with a transceiver must be installed in each device or computer. The transceivers act as access points through which signals are broadcast and received from each other. Currently, one of the most common wireless LAN infrastructures is the IEEE 802.11 (or Wi-Fi) technology.

IEEE 802.11 specifies the physical and Media Access Control (MAC) layers for operation of wireless LANs. The 802.11 standard provides for data rates from $11 \mathrm{Mb} / \mathrm{s}$ to $54 \mathrm{Mb} / \mathrm{s}$ (Pandya 2000). The term, Wi-Fi, is the global brand name across all 
markets for any 802.11-based wireles LAN product. Many computers, PDAs, and printers have begun to adopt Wi-Fi-or IEEE 802.11 as their major communication channels. There are three extensions in the 802.11 group technology which were considered for this project:

- 802.11.a provides up to $54 \mathrm{Mbps}$ transfer rate in the $5 \mathrm{GHz}$ band (referred to as Wi-Fi5);

- 802.11.b is the most popular extension and can provide up to $11 \mathrm{Mbps}$ data transfer rate in the $2.4 \mathrm{GHz}$ band. Because of the different radio frequency, $802.11 \mathrm{~b}$ devices are not compatible (accessible) with 802.1 la signals; and

- 80211.g provides up to a 20+ Mbps data transfer rate in the $2.4 \mathrm{GHz}$ band. Since the $11 \mathrm{~g}$ and $11 \mathrm{~b}$ are using the same radio frequency, $802.11 \mathrm{~g}$ devices are backward compatible with 802.11 b signals.

This research adopted the $802.11 \mathrm{~b}$ Wi-Fi technology to create a wireless LAN for the mobile GIS prototype. The wireless operating range of $\mathrm{Wi}-\mathrm{Fi}$ signals is up to $100 \mathrm{~m}$ (300 feet indoors) or $500 \mathrm{~m}$ (1500 feet outdoors), depending on environmental conditions. The wireless LAN in this prototype was used to provide access to the mobile Internet map server and image web server installed on a laptop computer.

One unique feature of this wireless mobile GIS prototype is that the process of setting the Wi-Fi communication was solely Internet Protocol (IP) based without relying on Domain Name Servers (DNS). Traditional web-based GIS applications utilize DNS for the naming and searching of machines (such as www.sdsu.edu or map.sdsu.edu). Since local wireless networks do not have dedicated computers for DNS, all the units in the wireless network prototype were accessed and identified by their own IP addresses. For example, the IP address of the notebook web server was 130.191.118.58 and the Pocket PC IP address was 130.191.118.56. The mobile GIS software package (ArcPAD) used in the project thus needed to specify an IP address to access Internet map services (Figure $3)$. The GIS users could also access the project web site by typing "130.191.118.58" rather than typing Domain Name (i.e., map.sdsu.edu).

\section{Customized Mobile GIS Software and Receiver Devices}

The mobile GIS software used in our prototype is ESRI ARCPAD 6.0. ArcPad is ESRI's mobile mapping and GIS software, which runs on portable computers using the Window CE operating system (Pocket PC). ArcPad can be integrated with a global positioning system (GPS) and act as a client to ArcIMS (ESRI 2002). The major challenge in setting up mobile GIS receivers is to create the link between GPS devices and the Pocket PCs. The research team tested two types of communication mechanisms: a direct serial cable link and wireless Bluetooth connection. The first approach used a specialized serial cable for the connection between Pocket PCs and GPS devices. A potential problem with this approach is that different Pocket PCs and PDAs require different types of cables, which may be difficult to obtain. Also, the portability of the hand-held units can be significantly reduced by the length and potential tangling of cables between the two devices. The second approach was to use a Bluetooth GPS card to connect to a Bluetooth-capable Pocket PC. Bluetooth is a wireless radio-based technology for personal device communications over short ranges (within 100 meters). After comparing the two methods, the research team preferred the Bluetooth GPS configuration over the cable-based configuration.

During the prototype testing, several basic GIS functions, such as distance measurement and object identification, were performed using ArcPAD to illustrate the capability of mobile GIS. Figure 4 shows a series of screen shot images captured directly from the Pocket PC using the ArcPAD toolbox. The distance measurement example was the distance measured between the SDSU parking structure and the Geography Department building (102.8 meters). The research team also customized the ArcPAD user interface to add new buttons designed for park rangers and environmental scientists using the Application Builder provided by ArcPAD. However, the research team experienced limitations in the existing GIS functions provided in the ArcPAD Application Builder, especially in the low-level data communication and networking functions.

This project utilized both cable and wireless communication mechanisms between the mobile GIS receiver and the GIS content server. During testing, GIS layers (roads, points of interest, ecologically sensitive plants, park boundary) were downloaded directly from a GIS workstation via USB cable connections. Later, large-sized, remotely sensed imagery was accessed from an ArcIMS server by ArcPad using a TCP/IP connection over a wireless LAN. Also, an updated GIS layer was uploaded back to the web server directly via the wireless network.

Another major customized client-side function was the creation of a real-time incident report and submission using the wireless environment. We utilized the Pocket Internet Explorer and HTML Form functions to create a field survey report with which we submitted field reports to a web server 
via wireless communication networks in near-real time. Figure 5 shows the report form displayed on the pocket Internet explorer with the submission confirmation.

Beside the ESRI ArcPAD software there are other, commercially available mobile GIS packages, such as MapXtend from MapInfo and IntelliWhere Location Server from Intergraph (Intergraph 2002). Due to the limitations of research time and budget, our prototype testing was limited to ArcPAD for our mobile software testing.

\section{Web-based GIS Content Server \\ and the Implementation Framework}

The project team created a web-based GIS content server by installing web server software and ArcIMS 4.0 (ESRI 2001) on a notebook computer. The server components included a web server (Microsoft IIS 5.0) and an Internet map server (ArcIMS 4.0). The web server provided HTMLform functions for near real-time incident reporting as mentioned in the previous section. The web server also acted as the middleware between the ArcIMS server and the mobile GIS clients. ArcIMS (image map server) was used to provide Internet mapping services for the ArcPAD software via a wireless LAN. Figure 6 illustrates the setting of the GIS content server on the notebook, which was mounted in a vehicle or located with a portable battery power station.

The major challenge in setting up the portable GIS content server was providing an appropriate power supply for the notebook computers and the wireless access router. The research team used a 300-watt power converter to convert DC power from an automobile cigarette lighter connection to two AC outlets that were used to power a notebook computer and a wireless access router. The project team also tested the mobile GIS prototype by utilizing a portable battery power station as the source of electricity to the mobile devices (Figure 6).

Portable power stations have the advantage of having compact configuration and better portability. However, a battery station can only support three to four hours of consecutive GIS operation, which may be a limitation for long-term field GIS operations. A vehicle-based power source can last longer than the portable battery power station. The research team tested the battery power source of a mid-size sedan which can provide five hours of power support without restarting the engine of the vehicle. With the engine running, the vehicle's battery could provide longer power support for wireless routers and GIS units.
Figure 7 illustrates the actual implementation framework for the wireless mobile GIS prototype described here. The framework follows a generic architecture of mobile GIS, with the server-side components being a GIS content server (notebook) and Internet mapping services (ArcIMS). The content server was connected directly to a Wi-Fi transceiver by a twisted pair ethernet cable. The Wi-Fi transceiver then broadcast the mapping services to, and received updated data from, the client-side components utilizing Pocket PCs with ArcPAD and Pocket Internet Explorer software.

The complete system is mobile and suitable for various types of field data collection, analysis and monitoring tasks. All mobile devices were equipped with GPS, GIS, and remotely sensed image display capabilities. To demonstrate the feasibility of mobile GIS in field applications, the project team created several user scenarios and tested the prototype at a remote field location in the Mission Trail Regional Park in San Diego. The next section highlights some major tasks and findings derived during the prototype testing.

\section{User Scenarios and Prototype Testing}

The purposes of the prototype testing were to demonstrate the capability of the wireless mobile GIS, to evaluate the feasibility of our prototype system, and to gather user feedback for future system improvement. The criteria used in the prototype testing were:

- Proof of concept-to ensure the prototype system functions properly without failure;

- Usability evaluation-to evaluate whether the prototype can meet the needs of users; and

- Field agent review-to document end-user comments and suggestions for improvement to the prototype design and system architecture issues.

The following user scenario was a typical habitat management task, which focused on detecting land-cover changes based on a real-time update of GIS data.

Test Date: January 15, 2003

\section{Task Description}

Mission Trails Region Park (MTRP) rangers and private sector environmental scientists used the Pocket PC and GPS to perform a field mapping and GIS 
database updating task in order to locate the presence of new invasive plant infestations. This task is representative of habitat management fieldwork. The target mobile GIS tasks included:

- Connecting to the wireless ArcIMS Image server via WiFi connections from mobile GIS receivers;

- Reviewing several change detection images (MTRPchange) using mobile GIS software (ArcPAD);

- Adding new locations of invasive plants by using GPS; and

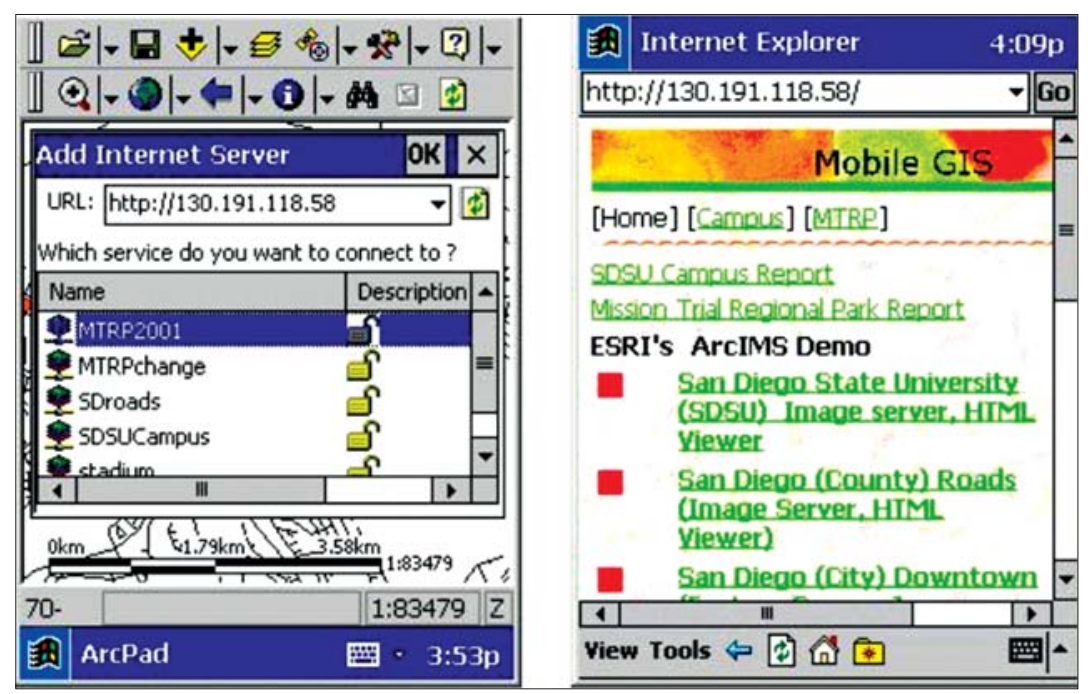

Figure 3. IP-based Internet map server and web sites.
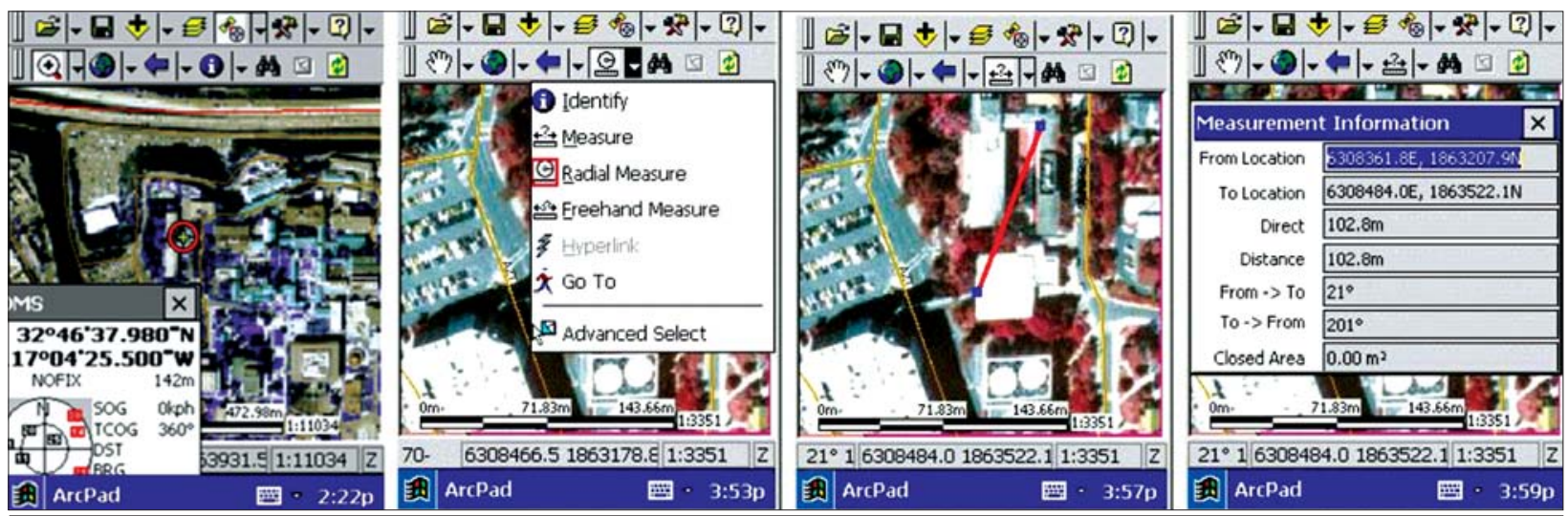

Figure 4. The basic GIS function in mobile GIS software.

- $\quad$ Sending updated GIS

layers (shapefiles) back to the server via mobile FTP software.

\section{Mobile GIS Solution}

The major goal of this scenario was to demonstrate the functionality of real-time wireless data update and GPS/GIS integration. A MTRP park ranger and a private sector environmental scientist participated as representative field users of a mobile GIS system. The research team used ArcPAD to access high-resolution Airborne Data Acquisition and Registration (ADAR) imagery of the study area within Mission Trial Regional Park (Figure 8) via wireless networks. Very high spatial resolution imagery

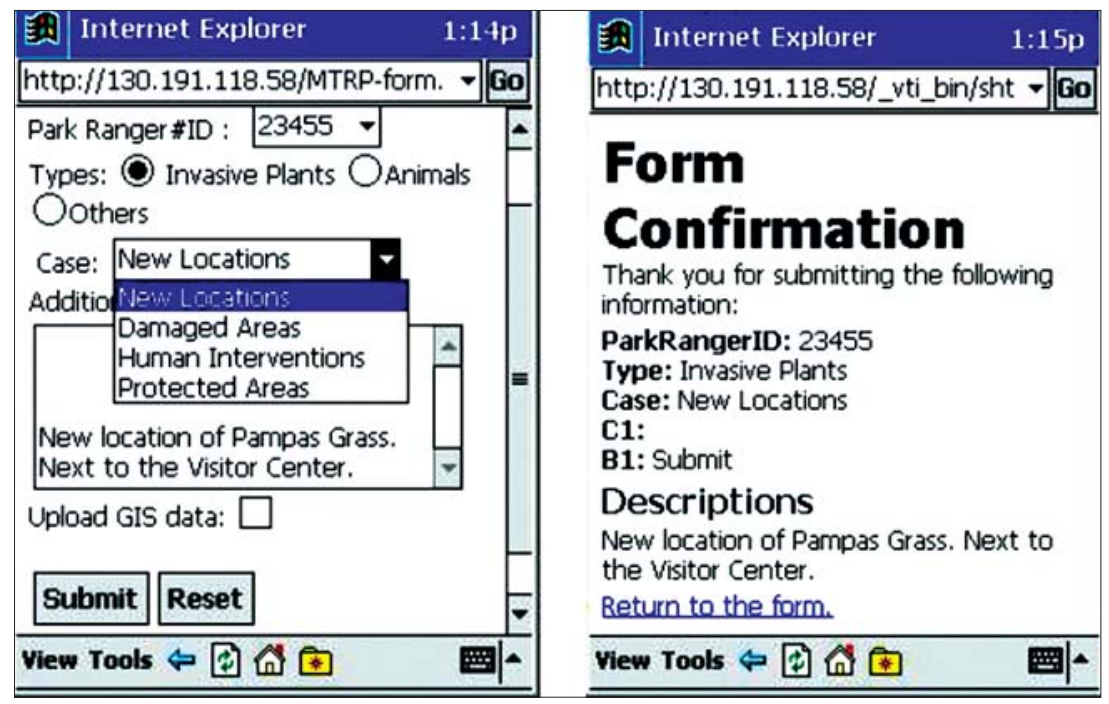

Figure 5. Real-time submission of a field survey report via a wireless network. such as ADAR offers strong possibilities for creating a comprehensive environmental monitoring process (Ehlers et al. 2003). Large imagery files 


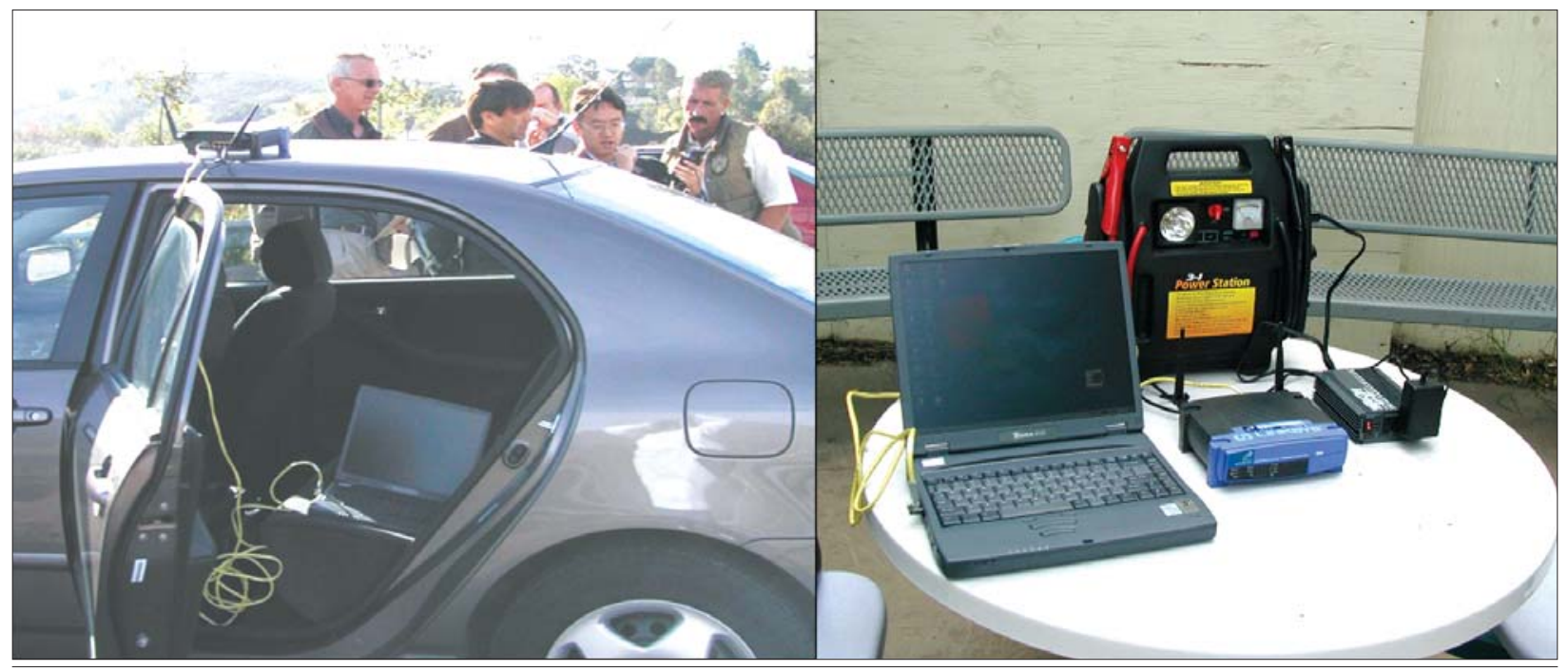

Figure 6. The GIS content server when mounted in a vehicle or connected to a portable power station.

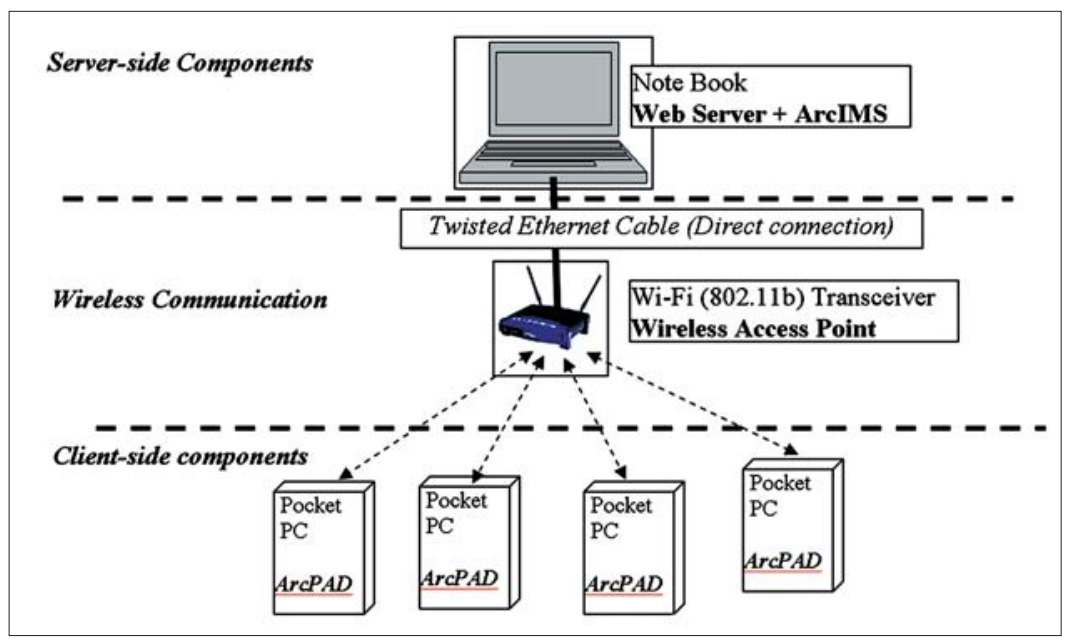

Figure 7. The implementation framework of mobile GIS. were stored in the notebook server and remotely accessed by ArcPAD. The test participants performed land-cover change assessments and mapping in areas adjoining a bicycle motocross (BMX) recreational site (white area on the right-side image in Figure 8).

The second task was to identify potential land cover changes by combining remotely sensed imagery with GPS. A change detection image product called MTRPchange was used to compare ADAR images captured during 2000 and 2001; the new image represented land-cover change based on that comparison.
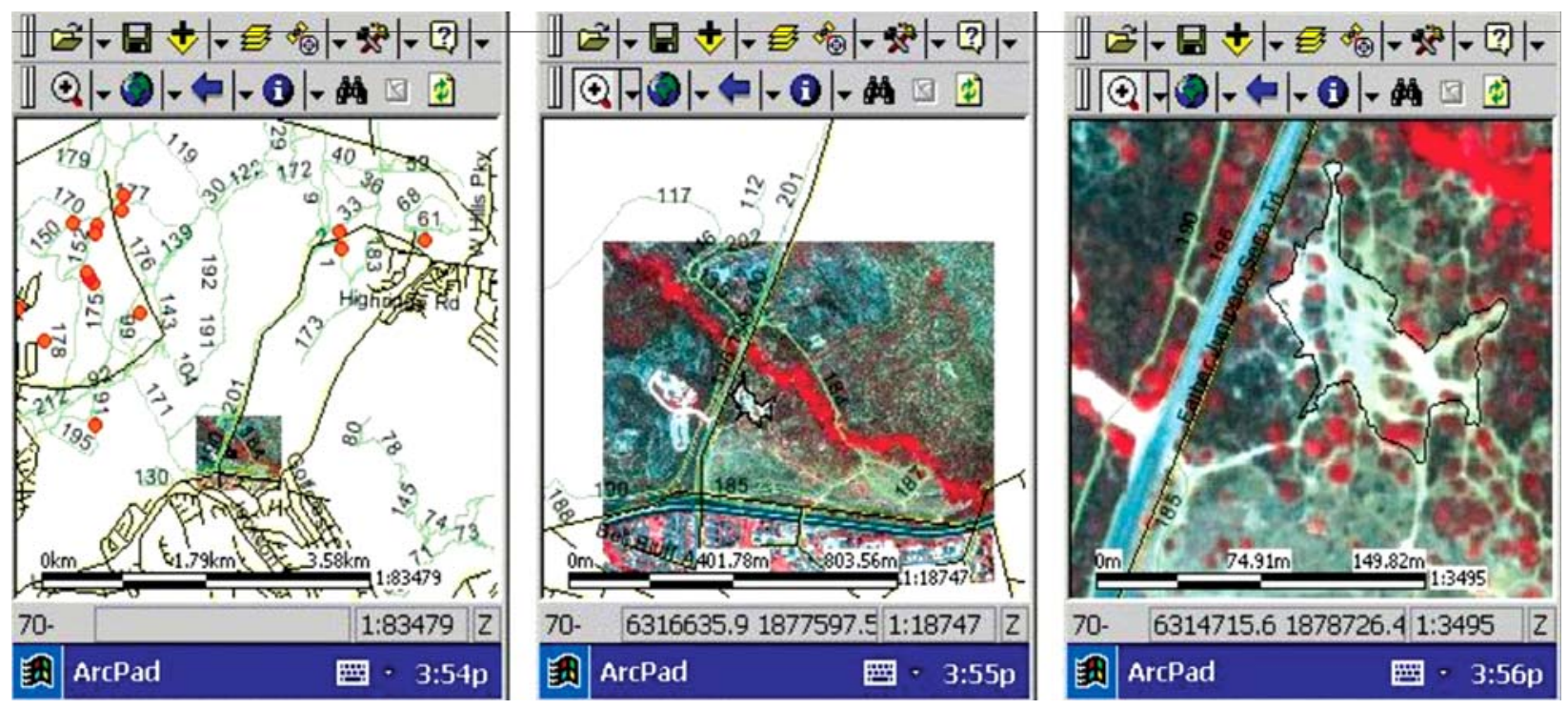

Figure 8. High-resolution ADAR imagery from a wireless Internet map server. 
Figure 9 shows the actual land-cover changes near the recreational BMX site in the Mission Trails Region Park, with the different colors indicating different types of land-cover change. For example, the green color indicates areas of increasing leaf cover within the study area. Test participants used GPS to locate their positions on the color-coded land-use map during assessments of land-cover changes around the BMX site.

The next task was to perform real-time update of land-cover changes and to send revised data back to the web server via the wireless network (Figure 10). Study participants mapped the new locations of invasive plants by recording their locations using ArcPAD correlated with GPS locations. The new map data set was uploaded back to the web server by using a Pocket PC-version of File Transfer Protocol (FTP) software called "CE FileCommander". Study participants also submitted field reports to the web server using HTML forms.

This use scenario combined Mobile GIS software (ArcPad), GPS, FTP, and wireless network communications to create a real-time GIS field survey and data update simulation. All the participants provided their feedback and comments to the research team during and after the scenario testing. The following items are summarized suggestions and observations based on user feedback.

- Mobile wireless mapping and data editing capabilities are superior to traditional hardcopy map editing;

- It is difficult to create a comprehensive wireless network environment over a wide area such as the Mission Trails Region Park due to terrain effects (mountainous terrain and numerous line-of-sight limitations). It is anticipated that the presence of wireless communication "dead zones" in the field may limit the widespread adoption of mobile GIS;

- Current software/hardware parameter settings for mobile GIS are still too complicated for the general users (individuals lacking mobile GIS training);

- Simplicity is essential to field user acceptance;

- GPS accuracy needs to be improved to less than a meter to make the application of mobile GIS feasible to various habitat monitoring and environmental resource management tasks; and

- The graphical user interface is difficult to see in bright light. Improved screen resolution may improve visibility.

\section{Conclusion and Suggestions for a Research Agenda}

The integration of mobile GIS technologies and wireless telecommunications was the key focus of this study, which utilized mobile GIS application software, global positional systems (GPS), and wireless networking technologies (IEEE 802.11b, Wi-Fi standard). The integrated mobile GIS framework provided natural-habitat conservation and land management program resource managers with integrated mobile geospatial information services that supported and helped optimize their field-based management tasks. The utilization of commercial off-the-shelf (COTS) mobile GIS software and hardware components help local government agencies to justify and obtain budgets to acquire mobile GIS systems. During user scenario testing, several challenges to the development of mobile GIS applications were identified. The following discussion summarizes these challenges and their possible future solutions.

The first challenge to implementing wireless mobile GIS is the short communications range of wireless networks and the requirement for broad bandwidth communications. Currently, most existing wireless LAN technologies are capable of only short-distance data transmissions ranging from 100 to 300 meters, which is not adequate for most fieldbased mobile GIS tasks. On the other hand, cellular phone networks have extensive spatial coverage for their wireless signals but lack broad bandwidth. To solve this problem, one possible solution would be to utilize broad bandwidth communication systems such as the High Performance Wireless Research and Education Network (HPREN) (http://hpwren.ucsd.edu) to provide long-distance wireless networking capability in the Wi-Fi mode. Also, the recent development of the IEEE 802.16 standard may become a potential wireless network solution for mobile GIS. The IEEE 802.16 standard defines the Wireless Metropolitan Area Network (MAN) Air Interface for broadband wireless access in large urban areas (http: //grouper.ieee.org/groups/802/16/index.html) with a scalable solution to extend fiber optic backbones. On the software development side, the design of new data compression technologies for both vector data and raster imagery via wireless networks may also facilitate the transmission of large datasets for mobile GIS applications in the future.

The second challenge is in the map display and user interface design of mobile GIS applications. Since the screen display of most mobile GIS receivers is significantly smaller than those of desktop computers, viewing maps and manipulate GIS layers on their 
small screens is rather difficult. In addition, most mobile GIS receivers do not have screens with highcontrast display when viewed in direct sunlight. The GIS industry and community will need to re-think the design issues of mobile GIS software and provide more intuitive and user-friendly user interfaces for mobile GIS applications. One potential solution is to adopt multimedia technologies (sound, animation, and hyperlinks) to improve the inherent restrictions on mobile devices (Gartner 2003). Also, by adopting 3D visualization of landscapes/buildings (Rakkolainen and Vainio 2001) and using augmented reality in urban environments (Haala and Bohm 2003), mobile GIS users could navigate local areas more efficiently and effectively.

The third challenge is to integrate Internet mapping technologies into mobile GIS. Most on-line GIS applications were designed originally for desktop clients and standardized web browsers (Plewe 1997; Tsou 2004). Many technologies, such as Java 2D API (Sun Microsystems, Inc. 2003), Java applets, and Microsoft Active Server Pages (ASP) functions, cannot be accessed or executed in Pocket PC environments or require additional plug-in software. Moreover, the heterogeneous software environment of desktop-based Internet mapping solutions may become another problem for the integration of mobile GIS applications.

One possible solution is to follow the OpenGIS Location Services (OpenLS) specifications developed by the Open GIS Consortium (OGC 2003a). OpenLS is an open software development platform for location-based application services, which utilizes XML-based Abstract Data Types (ADT) and the GeoMobility server (OGC 2003a; 2003b). The ADT was created by XLS, which is an XML-based language for location services. There are six major services defined by the OpenLS specifications: directory, gateway, location utility, presentation, route, and navigation services. Hopefully, the future development of OpenGL can be combined with other types of web services (Kolodziej 2002), such as Microsoft's .NET Framework or Sun's Java 2 Platform Enterprise Edition (J2EE) to provide more comprehensive technological frameworks for mobile GIS applications.

A fourth challenge is to provide intelligent mobile GIServices for different users with the help of software agents (Tsou and Buttenfield 2002). Different mobile GIS tasks will require distinct design of user interface, Internet mapping technologies, and communication channels. From a mobile GIS user's perspective, it is very difficult to access hundreds of different Internet map servers and to find out about appropriate location services at the same time. One possible solution is to adopt software agent technology to help users access or request data/images from multiple servers with automated mapping and GIS overlay functions. Software agents interact with different mobile GIS devices to provide customized user interfaces, to assign appropriate color and symbols for different GIS layers, and to search available wireless channels. The adoption of software agents might also solve the problem of information overload for mobile GIS users and provide automated data conversion and better integration methods for mobile GIS applications.

A final challenge is the data protection issue in wireless mobile GIS applications. Some mobile GIS applications may utilize classified or proprietary GIS data gathered from the field or through access to classified databases. The classified information needs to be protected from unauthorized access in both mobile GIS devices and via wireless communication channels. Currently there are very few preliminary solutions for the protection of sensitive GIS data, such as password protection and data-encrypted transmission.

The real challenge for securing mobile GIS applications is to create a hierarchical security framework to define different user groups (administrators, special-access users, regular users, guests) with different permissions to access various security levels of geodata from a single GIS content server. Such a solution will require not only the progress of future mobile GIS technologies, but also participation from both administration-level users and field workers. Moreover, some field-based data, such as census tracks and parcel records, may involve potential problems of locational privacy (Monmonier 2003). For example, a homeowner may not want to share his/her annual income information with a public utility worker who needs to repair the power line near his/her house. The GIS community needs to develop strategic guidelines for the issues of data protection and locational privacy.

In summary, this research demonstrated that an integrated mobile GIS framework can provide field personnel and first responders with mobile geospatial information services that directly support and help optimize their field-based collection, analysis, and resource management tasks. Mobile GIS is a very promising technology with strong demands from both field-based workers and GIS vendors. With the progress of new mobile GIS technologies, many future applications (such as homeland security, emergency rescue, real-time environmental monitoring, virtual tour guides, wildfire management, and vehicle navigation services) will benefit from, and ultimately rely on, mobile GIS technology. 


\begin{tabular}{|c|c|c|c|c|c|c|c|c|c|}
\hline 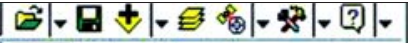 & 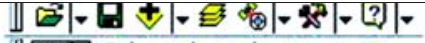 & II & & & & Layer & & & \\
\hline 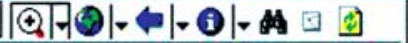 & \Ф & File Ed & & & & & & & Help \\
\hline & & $\tilde{\boldsymbol{\omega}}$ & I & 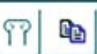 & 圆 & Layer & ber: 1 & F & \\
\hline & & Row & Value & & ass_N & ames & Color & Histogram & \\
\hline & & 0 & & 0 Unclassif & fied & & & 830954 & - \\
\hline & & 1 & & 1 Vegetati & on $->$ & Clear & & 9308 & \\
\hline & & 2 & & 2 2|Litter -> & Clear & & & 4773 & \\
\hline & & 3 & & 3 Leaf Cov & ler Inc & rease & & 18011 & \\
\hline & & 4 & & 4 Herbace & ous -3 & Litter & & 12184 & \\
\hline & & 5 & & 5 Herbace & ous - & Litter & & 5661 & \\
\hline & & 6 & & 6 Brightne & Ss Dec & rease & & 8992 & \\
\hline & & 7 & & $7 \mid$ Clear -> & Litter & & & 5566 & \\
\hline m. & $0 \mathrm{~m}$. & 8 & & $8 \mid \operatorname{Road} \mathrm{Pa}$ & & & & 5704 & \\
\hline 7. $6314385.11878988 .91: 3134$ & $6314385.11878988 .91: 955$ & & & & & & & & \\
\hline 固 - 11:36a & ArcPad & & & & & & & & \\
\hline
\end{tabular}

Figure 9. Land-cover changes (green color) near the bicycle motocross recreation site.

\section{ACKNOWLEDGEMENTS}

This paper forms a portion of the "Integrated Mobile GIS and Wireless Image Web Services for Environmental Monitoring and Management" project supported by NASA's Affiliated Research Center (ARC) at San Diego State University. Funding by the NASA ARC program and matching funds from NASA REASoN-0118-0209 project are acknowledged and greatly appreciated. The author wishes to thank John Kaiser, the ARC Program Coordinator, and Dr. Douglas Stow, the ARC program Principal Investigator, for their coordination efforts on this project, as well as the comments of the anonymous referees and editor.

\section{REFERENCES}

Angold, P. G., A. M. Gurnell, and P. J. Edwards. 1996. Locational errors in maps from environmental surveys and their implications for information extraction. Journal of Environmental Management 47: 341-54.

Crisp, N. 2003. Open location-based services: Technical brief (TB1034A). White paper. Integraph. [http: //www.intelliwhere.com. Last visited 12-16-2003].

Derekenaris, G., J. Garofalakis, C. Makris, J. Prentzas, S. Sioutas, and A. Tsakalidis. 2001. Integrating GIS, GPS and GSM technologies for the effective management of ambulances. Computer, Environment and Urban Systems 25: 267-78.

Ehlers, M., M. Gahler, and R. Janowsky. 2003. Automated analysis of ultra high resolution remote sensing data for biotope type mapping: New possibilities and challenges. ISPRS Journal of Photogrammetry E Remote Sensing 57:315-26.

ESRI (Environmental Systems Research Institute). 2001. Using ArcIMS. (User's Manual). Redland, California: ESRI Press.

ESRI (Environmental Systems Research Institute). 2002. Using ArcPAD: ArdPAD 6. Redlands, California: ESRI Press.
Gartner, G. 2003. Telecartography: Maps, multimedia and the mobile internet. In: Peterson, M.P. (ed.), Maps and the Internet. Oxford, U.K.: Elsevier Science Ltd. pp. 385-96.

Haala, N., and J. Bohm. 2003. A multi-sensor system for positioning in urban environments. ISPRS Journal of Photogrammetry \& Remote Sensing 58: 31-42.

Intergraph. 2002. Mobile resource management. White paper. Intergraph Mapping and Geospatial Solutions. [http:// www.intergraph.com/gis. Last visited: 12-16-2003].

Jagoe, A. 2002. Mobile location services: The definitive guide. Upper Saddle River, New Jersey: Prentice Hall.

Kolodziej, K. 2002. Real-time field data streaming. In: URISA 40th Annual Conference Proceeding, Chicago, Illinois, October 26-30, 2002.

Monmonier, M. 2003. The Internet, cartographic surveillance, and locational privacy. In: Peterson, M. P. (ed.), Maps and the Internet. Oxford, U.K.: Elsevier Science Ltd. pp. 97-113.

OGC (Open GIS Consortium). 2003a. OpenGIS location services (OpenLS), Parts 1-5: Core services. (version 0.5.0) OGC-03-006r1. Open GIS Consortium, Inc., Wayland, Massachusetts.

OGC (Open GIS Consortium) 2003b. OpenGIS location services (OpenLS), Part 6: Navigation services. (version 0.5.0) OGC-03-007r1. Open GIS Consortium, Inc., Wayland, Massachusetts.

Pandya, R. 2000. Mobile and personal communication systems and services. New York, New York: IEEE Press.

Peng, Z. R., and M. H. Tsou. 2003. Internet GIS: Distributed geographic information services for the Internet and wireless networks. New York, New York: John Wiley and Sons, Inc.

Plewe, B. 1997. GIS online: Information retrieval, mapping, and the Internet. Santa Fe, New Mexico: OnWord Press.

Pundt, H. 2002. Field data collection with mobile GIS: Dependencies between semantics and data quality. GeoInformatica 6(4): 363-80.

Pundt, H., and K. Brinkkotter-Runde. 2000. Visualization of spatial data for field-based GIS. Computers $\mathcal{E}$ Geosciences 26: 51-56. 


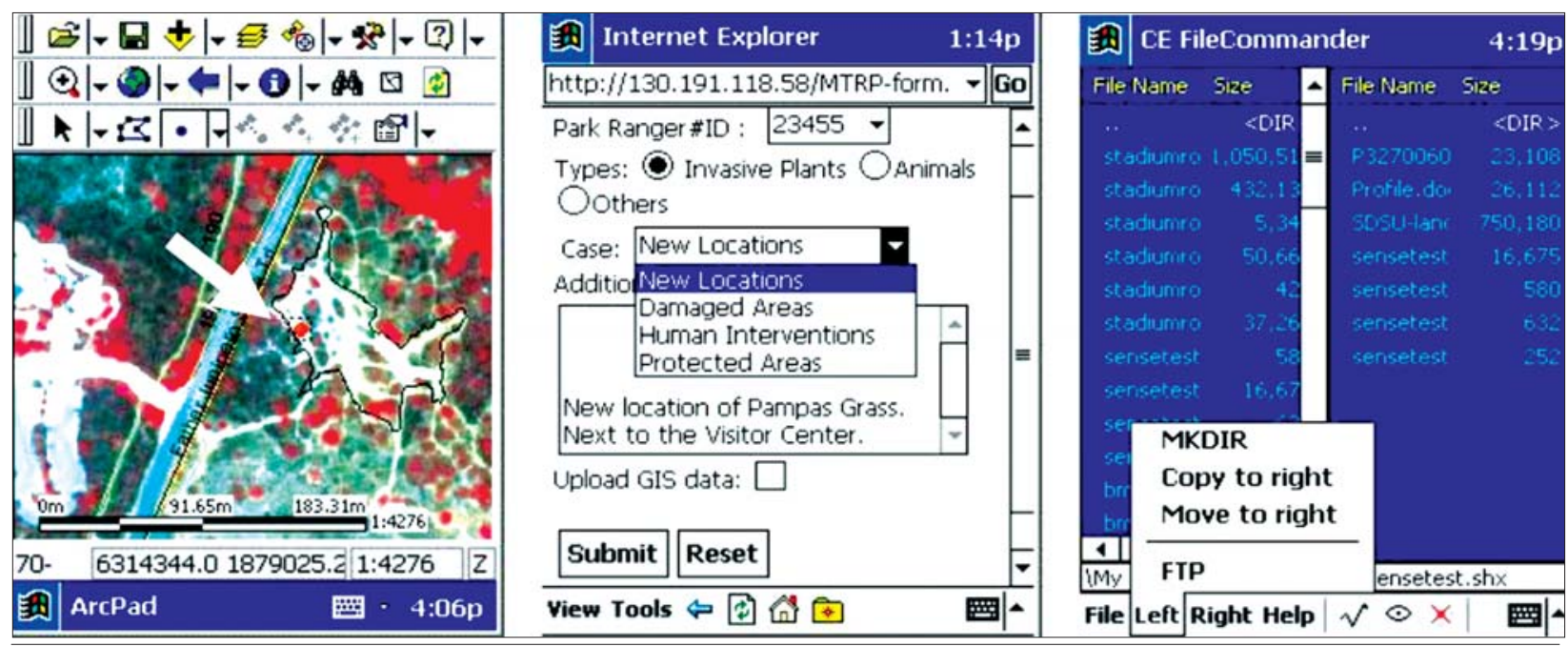

Figure 10. Real-time data upload function via wireless networks.

Rakkolainen I., and T. Vainio. 2001. A 3D city info for mobile user. Computers E Graphics 25: 619-25.

Sun Microsystems Inc. 2003. Java 2D API White Paper. [http: //java.sun.com/products/java-media/2D/whitepaper.html. Last visited: 12-10-2003].

Tsou, M. H., and B. P. Buttenfield. 2002. A dynamic architecture for distributing geographic information services. Transactions in GIS 6(4): 355-81.

Tsou, M. H. 2004. Integrating web-based GIS and on-line remote sensing facilities for environmental monitoring and management. Journal of Geographical Systems 6(2): 155-74.
Wintges, T. 2003. Geodata communication on personal digital assistants (PDA). In: Peterson, M. P. (ed.), Maps and the Internet. Oxford, U.K.: Elsevier Science Ltd. pp. 397-402.

Xue Y., A. P. Cracknell, and H. D. Guo. 2002. Telegeoprocessing: The integration of remote sensing, geographic information system (GIS), global positioning system (GPS) and telecommunication. International Journal of Remote Sensing 23(9): 1851-93. 